\title{
ANÁLISE DE PROPRIEDADES FÍSICO-QUÍMICAS EM LIGAS À BASE DE TITÂNIO TRATADAS PELO MÉTODO DE IMPLANTAÇÃO IÔNICA POR IMERSÃO EM PLASMA.
}

\author{
V. M. MEIRELES ${ }^{1,2}$, B. B. FERNANDES ${ }^{1}$, M. UEDA ${ }^{1}$, A. S. RAMOS 3 \\ ${ }^{1}$ Instituto Nacional de Pesquisas Espaciais, LAP/INPE \\ 2 Universidade Vale do Paraíba, UNIVAP \\ ${ }^{3}$ Universidade Federal de Alfenas, UNIFAL \\ E-mail para contato: viniciusmmeireles@gmail.com
}

\begin{abstract}
RESUMO - Ligas contendo titânio em sua estrutura são excelentes materiais utilizados em aplicações industriais que exigem elevada resistência à corrosão e às tensões mecânicas. No entanto, possuem suas limitações e, a fim de ampliar sua durabilidade, o presente estudo descreve o tratamento de ligas de titânio através da implantação iônica por imersão em plasma. Quando são submetidas a testes de corrosão e tribológicos, verifica-se que melhores resultados são adquiridos após a formação de camadas de nitretos na superfície das amostras. Análises de difração de raios-X e de espectroscopia por dispersão de elétrons permitiram a identificação química de tais superfícies.
\end{abstract}

\section{INTRODUÇÃO}

O titânio e suas ligas têm sido frequentemente utilizados em indústrias automobilísticas, aeroespaciais, marinhas, biomédicas e esportivas, devido à sua boa resistência a tensões mecânicas e a temperaturas elevadas. O principal interesse em aprimorar estas ligas está relacionado ao aumento de sua durabilidade e ampliar suas aplicações em diversos setores industriais, mesmo que já possuam boas condições de adaptação a ambientes agressivos, tais como altas tensões mecânicas e temperaturas elevadas (da Silva et al., 2006). De acordo com Zhecheva et al. (2005), Gorynin (1999) e Gurrappa (2003), as ligas de titânio são uma das mais importantes utilizadas na engenharia, pois possuem baixa densidade, alto ponto de fusão, baixo coeficiente de expansão térmica e são altamente resistentes à corrosão e à fadiga. Apesar das vantagens citadas anteriormente, essas ligas possuem baixa resistência ao desgaste e alto coeficiente de atrito, limitando seu uso em certas áreas, principalmente em certas aplicações biomédicas.

Com o intuito de melhorar as características da superfície das ligas, sem alterar suas propriedades volumétricas, a implantação iônica por imersão em plasma, mais conhecida como 3IP, faz parte de um grupo de tecnologias a fim de atingir tais propósitos. É uma técnica que permite o tratamento superficial de peças de geometrias complexas, podendo ser aplicados em ambientes quimicamente agressivos, garantindo ao material um aumento na dureza e na resistência à corrosão e ao desgaste (Mello et al, 2009; da Silva et al, 2006). A implantação consiste no bombardeamento da amostra por íons em uma câmara de vácuo, onde 
se produz o plasma. A amostra é pulsada com altas voltagens negativas $(2-300 \mathrm{kV})$, a fim de atrair os íons positivos para a superfície. Parâmetros como temperatura e tempo de tratamento influenciam na formação e espessura das camadas implantadas na superfície das ligas. No presente trabalho, almeja-se a comparação de tais propriedades entre as ligas não-tratadas e tratadas superficialmente por implantação iônica por imersão em plasma (3IP) de nitrogênio, afim de expandir a utilização destas ligas de titânio para outras aplicações diferentes das atuais.

\section{MATERIAIS E MÉTODOS}

As ligas de Ti-6Al-4V são ligas comerciais, obtidas em barras, sendo posteriormente cortadas para os testes e análises. Os principais materiais utilizados foram: solução de sílica coloidal (para o banho de ultrassom), lixas de carbeto de sílicio, pasta de diamante (para o polimento das peças), fios de tungstênio (suporte para a fixação das peças dentro da câmara de tratamento) e solução de cloreto de sódio (utilizada para os testes de corrosão).

As peças foram cortadas com disco de diamante nas dimensões $1,8 \times 1,75 \times 2,5 \mathrm{~mm}$ (largura, espessura e comprimento) e em seguida lixadas e polidas para a obtenção de uma superfície espelhada com poucos riscos. As amostras foram limpas em banho de ultrassom (durante 15 minutos) para o tratamento subsequente de plasma. Para a implantação pelo método de 3IP, as ligas de titânio foram fixadas por fios de tungstênio, que desempenha o papel do ânodo de descarga, sendo polarizado positivamente por tensões de corrente contínua de $700 \mathrm{~V}$ em relação à parede da câmara aterrada. Um catodo de óxido termiônico gerou elétrons primários auxiliando na quebra de descarga luminescente, que ocorre à faixa de pressão de $10^{-5}$ Torr, adequado para a técnica de 3IP. Os parâmetros do tratamento são citados na tabela 1:

Tabela 1 - Parâmetros utilizados para o tratamento por 3IP

\begin{tabular}{|c|c|c|c|c|c|c|}
\hline \multicolumn{2}{|c|}{ Fonte CC } & \multicolumn{2}{|c|}{$\begin{array}{l}\text { Filamento CA } \\
\end{array}$} & \multirow{2}{*}{$\begin{array}{c}\begin{array}{c}\text { Pulsos } \\
(\mathrm{kV} ; \mu \mathrm{s} ; \mathrm{Hz})\end{array} \\
\end{array}$} & \multirow{2}{*}{$\begin{array}{l}\text { Tempo } \\
\text { (min.) }\end{array}$} & \multirow{2}{*}{$\begin{array}{c}\text { Temperatura } \\
\left({ }^{\circ} \mathrm{C}\right)\end{array}$} \\
\hline Tensão(V) & Corrente (A) & Tensão (V) & Corrente (A) & & & \\
\hline $80-150$ & $0,2-1,3$ & $5-5,4$ & $10-16$ & $7 ; 30 ; 400$ & 60 & 850 \\
\hline
\end{tabular}

A fim de obter a análise das fases presentes em regiões superficiais das ligas, medições feitas através de difração de raios X (DRX) foram realizadas em um difratômetro Philips (modelo PW3719) no modo padrão de $2 \theta$ (voltagem a $40 \mathrm{kV}$ e corrente a $45 \mathrm{~mA}$ ). A caracterização morfológica da estrutura das peças tratadas e não tratadas por 3IP, foram realizadas através da microscopia eletrônica de varredura (MEV), utilizando também, EDS para determinar a composição química presente nas amostras. Ensaios de desgaste foram realizados em um tribômetro do tipo pin-on-disc.

A resistência à corrosão das ligas foi testada em solução de $\mathrm{NaCl}$ 3,5\% (em massa), com $\mathrm{pH}=6$. Os testes foram realizados através da utilização do equipamento Autolab PGSTAT302N. Foi utilizada uma célula eletrolítica convencional com três eletrodos, um eletrodo de referência de $\mathrm{Ag} / \mathrm{AgCl}$, e um fio de platina como contra-eletrodo. A tensão variou de $-1,0$ a $1,5 \mathrm{~V}$ com taxa de varredura de $1,0 \mathrm{mV} / \mathrm{s}$. 


\section{RESULTADOS E DISCUSSÕES}

Através de DRX, é possível realizar a análise das fases presentes nas ligas de Ti-6Al$4 \mathrm{~V}$, antes e após o tratamento por 3IP. Foram utilizadas seis amostras na análise, sendo as ligas não tratadas por 3IP identificadas como TAV (1 e 2), iguais entre si, e as que receberam o tratamento foram denominadas como PIII (1, 2, 3 e 4), sendo $30 \mathrm{~mm}$ a distância entre as peças dentro da câmara de tratamento. Os gráficos foram obtidos em duplicata para facilitar a visualização dos picos das fases presentes nas ligas, de acordo com os difratogramas da Figura 1:

Figura 1 - Difratogramas de raios-X antes e após o tratamento por 3IP.
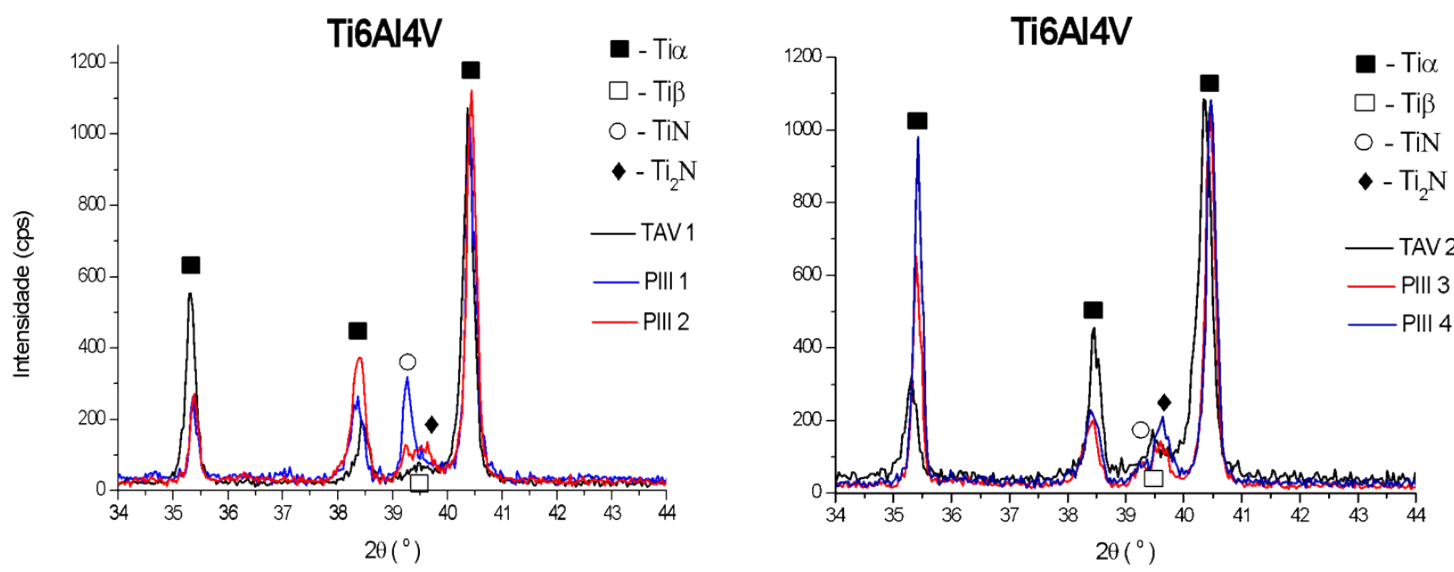

A amostra PIII 1 encontrava-se mais próxima ao emissor de elétrons durante a implantação iônica e PIII 4, a mais distante. A distância do emissor de elétrons para o tratamento resultou em diferentes intensidades nos picos das fases dos nitretos (localizados entre os ângulos $39^{\circ}$ e $40^{\circ}$ ) e espessura no revestimento das amostras (variando entre 1 a $2 \mu \mathrm{m})$. Na superfície das ligas sem o tratamento há a presença majoritária da fase Tia (estrutura hexagonal compacta) e minoritária da fase Ti $\beta$ (estrutura cúbica de face centrada). Em PIII 1, o pico de TiN encontra-se em maior intensidade do que nas outras amostras analisadas. Em PIII 2, os picos das fases $\mathrm{TiN}_{\mathrm{N}} \mathrm{Ti}_{2} \mathrm{~N}$ encontram-se em valores próximos de intensidade, com menor valor de intensidade de TiN, quando comparada com PIII 1. Em PIII 3 , a presença de $\mathrm{Ti}_{2} \mathrm{~N}$ aumenta, com a consequente diminuição na intensidade da fase TiN. E na amostra PIII 4, a intensidade da fase TiN diminui bruscamente, conferindo à liga maior intensidade da fase $\mathrm{Ti}_{2} \mathrm{~N}$. A diminuição de alguns picos da fase Ti $\alpha$ nas ligas tratadas por 3IP deve-se à sua presença em menor quantidade na superfície e pela formação de nitretos a partir de átomos de titânio de planos cristalográficos específicos.

Análises obtidas através de MEV demonstram uma alteração significativa na morfologia da superfície, tornando as ligas mais rugosas após o tratamento, conforme a Figura 2. A maior presença de poros nas ligas tratadas deve-se à heterogeneidade da 
superfície, sendo esta proveniente da implantação de nitrogênio na superfície durante o tratamento.

Figura 2 - Imagens obtidas no MEV das ligas de Ti-6Al-4V

(a) não tratada

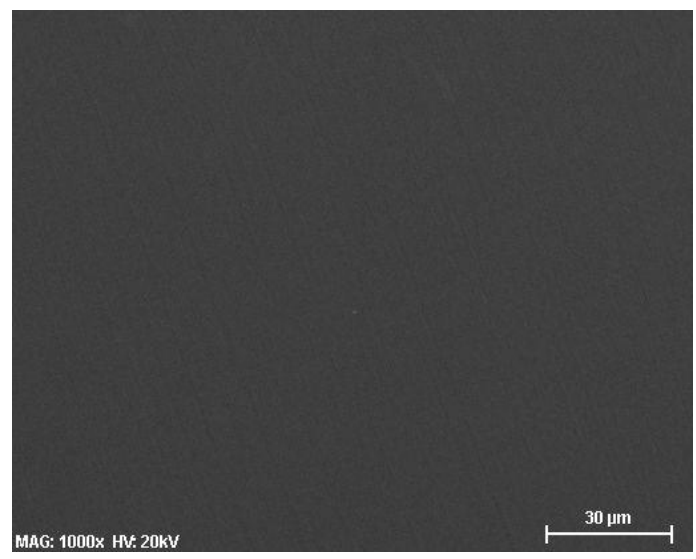

(b) tratada por 3IP

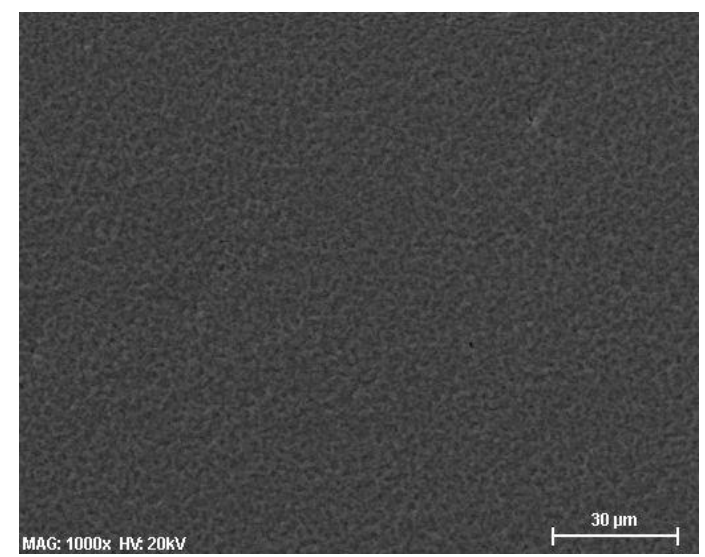

Utilizando espectroscopia por dispersão de elétrons (EDS), foi possível quantificar que as ligas tratadas apresentaram, em média, 41,98\% (at.) de titânio, 1,5\% (at.) de alumínio e o vanádio não foi detectado nas camadas superficiais. O tratamento por 3IP também garantiu às ligas significativa redução no coeficiente de atrito e na taxa de desgaste. As amostras apresentaram diferentes valores nos ensaios de tribologia, devido à distância de cada amostra a partir do emissor de elétrons durante a implantação, de acordo com a Figura 3.

Figura 3 - Ensaio de tribologia das ligas Ti-6Al-4V.

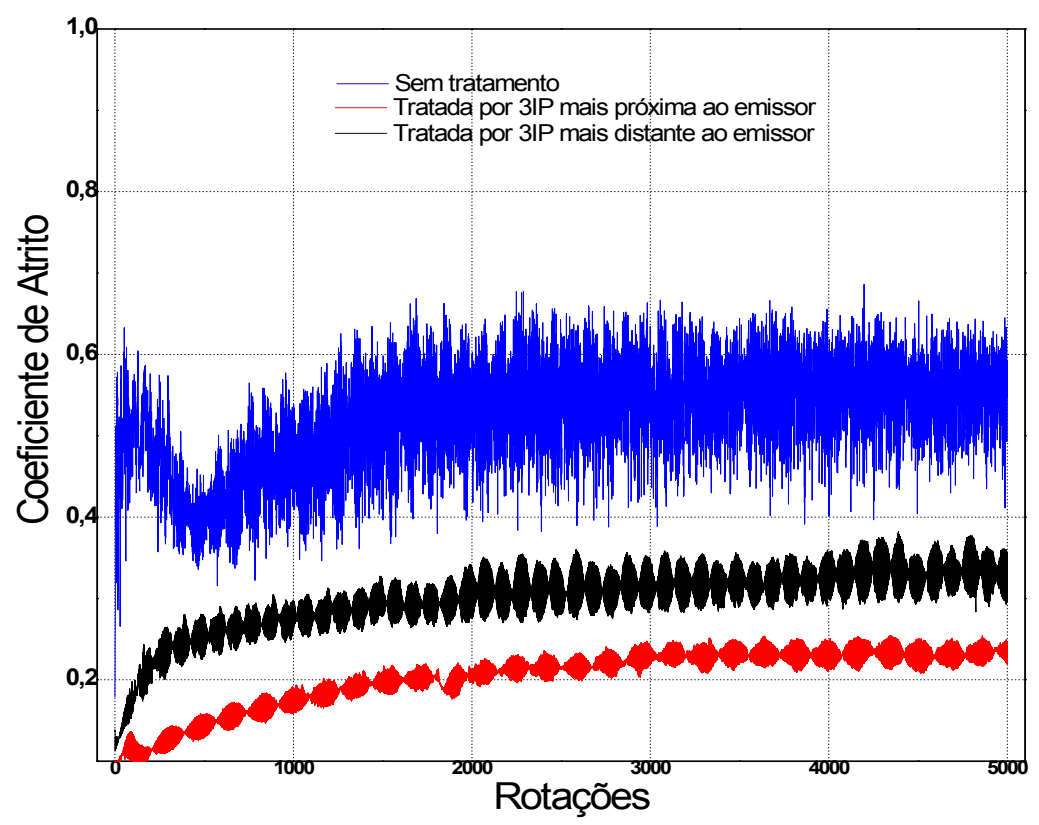


Submetidas a testes de corrosão, as ligas Ti-6Al-4V tratadas por 3IP, demonstraram um deslocamento de potencial para valores mais positivos e diminuição em grande parte da região anódica, indicando que a camada de nitreto, proveniente do tratamento, garantiu maior resistência à corrosão, de acordo com as curvas potenciodinâmicas da Figura 4.

Figura 4 - Curvas Potenciodinâmicas das ligas de Ti-6Al-4V.

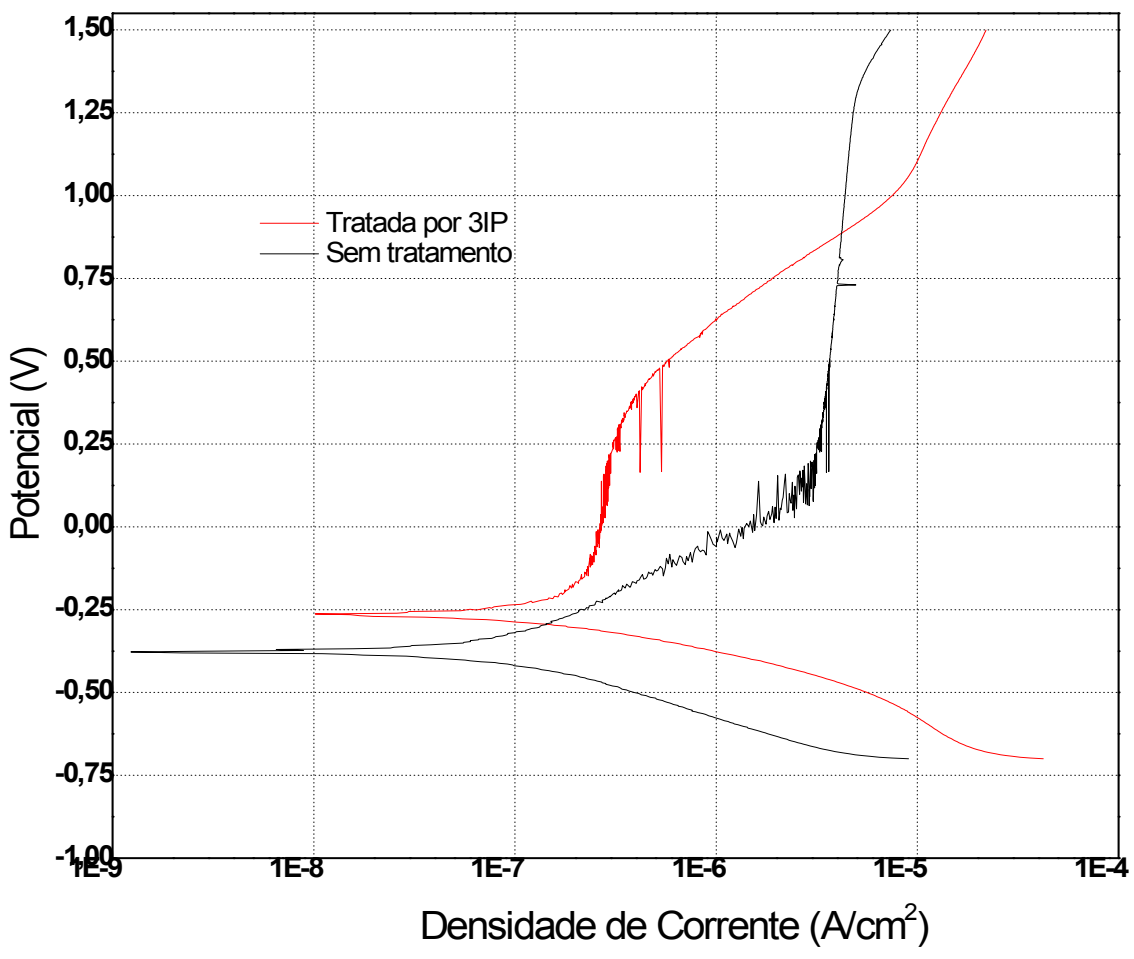

\section{CONCLUSÃO}

Após o tratamento por 3IP, o aumento na espessura das camadas de nitretos influencia diretamente na mudança do coeficiente de atrito e no aumento da resistência ao desgaste e corrosão. Análises obtidas através da microscopia eletrônica de varredura (MEV) utilizando EDS possibilitaram obter a quantificação da composição de fases e a morfologia das ligas de titânio, antes e após o tratamento. Através de raios-X, notou-se que a distância do emissor de tratamento das ligas influencia diretamente na formação de fases heterogêneas. Conforme a distância aumenta, menos nitrogênio é inserido na superfície e mais $\mathrm{Ti}_{2} \mathrm{~N}$ é formado em vez de TiN. Em análises de morfologia comprovou-se que, após o tratamento por 3IP, as ligas exibem superfícies mais rugosas e maior dureza. 


\section{REFERÊNCIAS}

DA SILVA, L.L.G.; UEDA, M.; DA SILVA, M.M.; CODARO, E.N. Effects of plasma immersion ion implantation (PIII) of nitrogen on hardness, composition and corrosion resistance of Ti-6Al-4V alloy. Braz. J. Phys., v.36, p. 990-993, 2006.

GORYNIN, I.V. Titanium alloys for marine application. Mater. Sci. Eng., v. 263, p.112-116, 1999.

GURRAPPA, I. Characterization of titanium alloy Ti-6Al-4V for chemical, marine and industrial applications. Mater. Charact., v. 51, p. 131- 139, 2003.

MELLO, C.B.; UEDA, M.; LEPIENSKI, C.M.; REUTHER, H. Tribological changes on SS304 stainless steel induced by nitrogen plasma immersion ion implantation with and without auxiliary heating. Appl. Surf. Sci., v. 256, p. 1461-1465, 2009.

ZHECHEVA, A.; SHA, W.; MALINOV, S.; LONG, A. Enhancing the microstructure and properties of titanium alloys through nitriding and other surface engineering methods. Surf. Coat. Tech., v. 200, p. 2192-2207, 2005. 